\title{
DAMPAK ENVIROMENTAL CONCERN, ADVERTISEMENT DAN ELECTRONIC WORD OF MOUTH PADA GREEN PURCHASE BEHAVIOR
}

\author{
Ming Ming Lukiarti \\ Sekolah Tinggi Ilmu Ekonomi STIE YPPI Rembang, Indonesia
}

$\varangle$ Corresponding Author:

Nama Penulis: Ming Ming Lukiarti

E-mail: mangmingluk@gmail.com

\begin{abstract}
The movement to save the environment is increasingly widespread when it is known that the earth's temperature is increasing along with global warming which is difficult to stop. Consumers are increasingly aware of the importance of caring for the environment by buying green products and services, in addition to caring for the surrounding environment as well as to maintain a healthy body. For example, hand-drawn batik with natural dyes, cloth sanitary napkins, clody (baby diapers), plastic that can be recycled and is easily biodegradable, agricultural products and organic cosmetics and other green products (Lukiarti, 2019). This study discusses the impact of three independent variables, namely environmental concern, advertisement and electronic word of mouth on the dependent variable, namely green purchase behavior. The objects in this study are consumers of green products in Indonesia. This study uses the SPSS analysis tool, by calculating the relationship of the independent variables partially and simultaneously to the dependent variable and calculating the weight of the influence of the independent variable on the dependent variable with a determination test. test results show that environmental concerns, advertisements and E-WOM simultaneously have a positive and significant impact on green purchase behavior.
\end{abstract}

Keywords: Enviromental Concern, Adcertisement, E-WOM, Green Purchase Behavior.

\begin{abstract}
Abstrak: Gerakan penyelamatan lingkungan semakin marak ketika diketahui suhu bumi semakin meningkat seiring dengan pemanasan global yang sulit dihentikan. Konsumen semakin sadar akan pentingnya sikap peduli lingkungan dengan membeli produk dan jasa hijau, selain untuk merawat kelestarian sekitar juga demi menjaga kesehatan tubuh. Seperti misal batik tulis dengan pewarna alami, pembalut wanita dari kain, clody (popok bayi), plastik yang bisa didaur ulang dan mudah terurai di alam, produk pertanian dan kosmetik organik serta produk hijau lainnya (Lukiarti, 2019). Penelitian ini membahas dampak tiga variabel independen yaitu enviromental concern, advertisement dan electronic word of mouth terhadap variabel dependen yaitu green purchase behavior. Obyek dalam penelitian ini adalah konsumen produk hijau yang berada di Indonesia. Penelitian ini menggunakan alat analisis SPSS, dengan menghitung hubungan variabelvariabel independen secara parsial dan simultan terhadap variabel dependen serta menghitung bobot pengaruh variabel independen terhadap variabel dependen dengan uji determinasi. Dari hasil uji reliabilitas dan validitas sudah diketahui bahwa pernyataan pada kuesioner sudah reliabel dan valid. Hasil uji parsial menyatakan bahwa enviromental concern, advertisement dan E-WOM secara parsial berdampak positif dan signifikan terhadap green purchase behavior.
\end{abstract}

Kata kunci: Enviromental Concern, Adcertisement, E-WOM, Green Purchase Behavior. 


\section{PENDAHULUAN}

Gerakan penyelamatan lingkungan semakin marak ketika diketahui suhu bumi semakin meningkat seiring dengan pemanasan global yang sulit dihentikan. Perusahaan-perusahaan global memutakhirkan sistem pemasarannya dengan merubah paradigma pemasaran konvensional menjadi konsep pemasaran hijau. Manusia semakin dituntut untuk peduli pada lingkungan dan mengendalikan pola konsumsi. Pergerseran gaya hidup akan terjadi seiring dengan gencarnya kampanye peduli lingkungan baik itu secara langsung maupun melalui media sosial. Banyak sekali informasi yang mudah didapatkan mengenai bagaimana cara merubah gaya hidup yang lebih peduli kepada lingkungan. Kesadaran masyarakat di berbagai belahan dunia tentang pentingnya menjaga kelestarian lingkungan hidup semakin meningkat. Terjadinya pemanasan global (global warming) membuat masyarakat semakin hati-hati menggunakan berbagai produk yang dikhawatirkan dapat menambah level pemanasan global pada level yang membahayakan umat manusia.

Saat ini konsumen menjadi lebih peduli dengan masalah hijau dan menjadikan penghijauan di segala aspek sebagai motivasi mereka dan akan diterapkan secara terus-menerus sehingga menjadi gaya hidup mereka (Hayat dan Ahmed, 2017). Di Jakarta pernah diadakan acara kesadaran hijau, yaitu mematikan listrik selama satu jam di waktu tertentu sebagai kampanye hemat energi yang diakui sebagai jam Bumi untuk mengurangi dampak lingkungan di bumi. Tujuannya untuk menyelamatkan lingkungan dari berbagai jenis bahaya kerusakan lingkungan yang disebabkan oleh listrik, yang kita ketahui bahan bakar listrik di Indonesia menggunakan energi fosil yang berisiko tinggi terhadap kerusakan alam.

Menurut Shrum et.al. (1995) konsumen hijau adalah mereka yang perilaku pembeliannya dipengaruhi oleh kepedulian lingkungan. Saat ini, lebih banyak konsumen yang cenderung mengungkapkan keprihatinan lingkungan mereka dengan membeli produk dan jasa ramah lingkungan. Hijau sebagai visi adalah kenyataan yang membutuhkan pemahaman lebih fungsional yang membantu pemasar untuk mendesain strategi pemasaran dalam memenuhi kebutuhan konsumen hijau (D’Souza, 2004). 
Kesadaran masyarakat yang meningkat tentang pentingnya menjaga kelestarian lingkungan hidup membuat banyak produsen dari berbagai macam produk mulai beralih menggunakan bahan-bahan yang tidak merusak lingkungan atau istilah lainnya bahan yang ramah lingkungan.. Bahan-bahan yang dimaksud tidak hanya bahan baku produk melainkan juga menyangkut material lainnya seperti kemasan produk, pelabelan, karton pembungkus dan lain sebagainya (Situmorang, 2011). Produsen yang tidak ingin ditinggal oleh pelanggannya harus segera mengubah konsep pemasarannya, karena lambat-laun kesadaran lingkungan pada konsumen akan tercipta dan konsumen akan lebih selektif untuk memilih produk yang akan dikonsumsi.

Konsumen semakin sadar akan pentingnya sikap peduli lingkungan dengan membeli produk dan jasa hijau, selain untuk merawat kelestarian sekitar juga demi menjaga kesehatan tubuh. Seperti misal batik tulis dengan pewarna alami, pembalut wanita dari kain, clody (popok bayi), plastik yang bisa didaur ulang dan mudah terurai di alam, produk pertanian dan kosmetik organik serta produk hijau lainnya (Lukiarti, 2019). Perusahaan berlomba-lomba untuk menciptakan produk ramah lingkungan dikarenakan selain pentingnya memiliki kesadaran lingkungan, juga karena prospek bisnis hijau juga sangat menjanjikan di masa mendatang. Lambat laun, manusia akan menyadari pentingnya memilih produk yang ramah lingkungan dan sehat untuk dikonsumsi. Perubahan paradigma konsumen terhadap pola konsumsi akan menjadi tren yang menciptakan peluang pasar baru.

Konsep green marketing menjadi konsep yang paling sering dibicarakan dan menjadi fokus utama dari perusahaan-perusahaan dunia. Tidak terkecuali bagi jenis usaha kecil menengah atau yang dikenal dengan istilah Usaha Kecil Menengah (UKM). Adanya tuntutan konsumen secara global mengharuskan UKM untuk memiliki orientasi green marketing. Dalam hal ini, produk ataupun jasa yang dihasilkan harus memiliki konsistensi yang tinggi terhadap nilai-nilai lingkungan yang meliputi seluruh aspek yang ada dalam usahanya misalnya dalam pengembangan produk, produksi, pengelolaan energi dan limbah, proteksi konsumen, kebijakan lingkungan dan sosial.

Ada banyak jenis media yang terdiri dari radio, media cetak dan televisi serta 
internet yang bekerja untuk mendapatkan perhatian dari konsumen (Hayat dan Ahmed, 2017). Setiap hari kita dapat melihat dan mendengar sejumlah besar kegiatan iklan yang menarik dan kreatif seperti aktivitas online di televisi, radio dan internet dll. Dan aktivitas offline di koran, majalah, papan iklan, dll. Di antara berbagai media ini, iklan televisi dianggap sebagai lebih menarik dan ditonton oleh khalayak ramai. Jadi bisa dikatakan televisi dianggap sebagai salah satu media yang ideal untuk beriklan di mana waktu "penuh perhatian" dapat dihabiskan oleh audiens. Namun itu adalah peran pemasar untuk membuat iklan begitu kreatif untuk mendapatkan perhatian dari konsumen dan mendapatkan respons yang diinginkan dari konsumen (Vivekananthan, 2010). Diperlukan bahwa periklanan hijau sangat informatif dan kreatif sehingga pelanggan akan terpengaruh untuk pembelian produk ramah lingkungan.

Studi Nielsen menyebutkan bahwa konsumsi media digital dan media konvensional kini saling melengkapi dalam kehidupan sehari-hari. Hanya saja, porsinya berbeda-beda pada tiap generasi. Misalkan Generasi Z (10-19 tahun), sebanyak 97 persen Generasi Z masih menonton televisi, 50 persen mengakses internet, 33 persen mendengarkan radio, 7 persen menonton televisi berbayar dan 4 persen membaca media cetak. Pada Generasi Milenial (20 - 34 tahun), 96 persen dari mereka menonton televisi dan 58 persen mengakses internet. Kebalikannya adalah Generasi X (35-49 tahun) yang menonton televisi (97 persen), mendengarkan radio (37 persen) dan mengakses internet (33 persen), Sementara, 95 persen dari Generasi Baby Boomers (50 - 64 tahun) menonton televisi, 32 persen mendengarkan radio dan 9 persen mengakses internet (Kompas.com).

Word of mouth (WOM) dianggap sebagai nasihat informal yang diterima oleh konsumen dan umumnya bersifat interaktif, instan, dan bebas dari bias komersial (Hayat dan Ahmed 2017). Word of mouth communication (WOM) atau komunikasi dari mulut ke mulut merupakan proses komunikasi yang berupa pemberian rekomendasi baik secara individu maupun kelompok terhadap suatu produk atau jasa yang bertujuan untuk memberikan informasi secara personal (Kotler dan Keller, 2012). Goldsmith dan Horowitz (2006) menyatakan bahwa penggunaan internet telah mengubah cara konsumen berkomunikasi dan 
berbagi pendapat atau ulasan mengenai produk atau jasa yang pernah dikonsumsi. Proses komunikasi antar konsumen melalui internet dikenal dengan Electronic Word-of-Mouth (e-WOM). Penelitian yang dilakukan oleh Jimenez dan Mendoza (2013), menunjukkan bahwa e-WOM memiliki pengaruh terhadap perilaku konsumen sebelum konsumen memutuskan untuk membeli sebuah produk atau jasa.

Menurut Rashid (2009), green purchase behavior dikonsepsikan sebagai kemungkinan dan kemauan seseorang untuk memberikan preferensi lebih atas produk ramah lingkungan dibandingkan dengan produk tradisional dalam keputusan pembelian seseorang. Kemampuan untuk mengkaji perilaku pembelian produk ramah lingkungan di Indonesia secara keseluruhan akan sangat bermanfaat karena Indonesia memiliki segmen pasar yang sangat luas (Hiqmah, 2016).

Berdasarkan latar belakang tersebut maka diperlukan penelitian lebih lanjut mengenai dampak dari enviromental concern, advertisement, dan electronic word of mouth (e-WOM) terhadap green purchase behavior.

\section{METODE PENELITIAN}

Jenis penelitian ini adalah penelitian kuantitatif. Menurut Sugiono (2008), metode kuantitatif adalah pendekatan ilmiah yang memandang suatu realitas itu dapat diklasifikasikan, konkrit, teramati dan terukur, hubungan variabelnya bersifat sebab akibat dimana data penelitiannya berupa angka-angka dan analisisnya menggunakan statistik. Data dalam penelitian ini diperoleh dari konsumen produk hijau yang ada di beberapa kota di Indonesia. responden penelitian ini adalah konsumen produk hijau di Kota Rembang, dan yang telah bersedia mengisi kuesioner berjumlah 300 responden. Teknik pengambilan sampel dengan metode purposive sampling, sedangkan analisis datanya menggunakan regresi linier berganda dengan bantuan program aplikasi SPSS 22

\section{HASIL PENELITIAN}

\subsubsection{Gambaran Umum Responden}

Data deskriptif tentang responden menurut jenis kelamin dapat dilihat melalui tabel 1 berikut ini: 
Tabel 1. Responden Menurut Jenis Kelamin

\begin{tabular}{ccc}
\hline Jenis Kelamin & Jumlah & Persentase (\%) \\
\hline Laki-laki & 144 & $48 \%$ \\
Perempuan & 156 & $52 \%$ \\
Jumlah & 300 & $100 \%$ \\
\hline
\end{tabular}

Sumber: Data primer yang diolah, 2021

Dari tabel diatas dapat dilihat bahwa responden berjenis kelamin perempuan lebih banyak yaitu 156 responden (52\%) sedangkan yang berjenis kelamin laki-laki ada 144 orang (48\%).

Tabel 2. Responden Menurut Usia

\begin{tabular}{ccc}
\hline Usia & Jumlah & Persentase (\%) \\
\hline $\mathbf{1 8 - 2 2}$ tahun & 69 & $23 \%$ \\
$\mathbf{2 3 - 2 7}$ tahun & 108 & $36 \%$ \\
$\mathbf{2 8}-32$ tahun & 48 & $16 \%$ \\
33-37 tahun & 39 & $13 \%$ \\
$>$ 37 tahun & 36 & $12 \%$ \\
Jumlah & 300 & $100 \%$ \\
\hline
\end{tabular}

Sumber: Data primer yang diolah, 2021

Dari tabel diatas dapat dilihat bahwa responden berusia 23-27 tahun lebih dominan yaitu berjumlah 108 responden (36\%), berusia 18-22 tahun berjumlah 69 responden (23\%), berusia 28-32 tahun berjumlah 48 responden (16\%), berusia 33-37 tahun 39 responden (13\%) dan yang berusia $>36$ tahun sebanyak 36 responden (12\%).

Tabel 3. Responden Menurut Pendidikan Terakhir

\begin{tabular}{ccc}
\hline Pendidikan Terakhir & Jumlah & Persentase (\%) \\
\hline < SMP & 0 & $0 \%$ \\
SMA & 90 & $30 \%$ \\
DIPLOMA & 27 & $9 \%$ \\
SARJANA & 135 & $45 \%$ \\
PASCASARJANA & 48 & $16 \%$ \\
Jumlah & 300 & $100 \%$ \\
\hline
\end{tabular}

Sumber: Data primer diolah, 2021

Dari tabel diatas dapat dilihat bahwa yang paling dominan adalah pendidikan terakhir Sarjana (S1) yaitu sebanyak 135 responden (45\%), kemudian SMA sebanyak 90 responden (30\%), Diploma sebanyak 27 reaponden (9\%), Pascasarjana sebanyak 48 responden (16\%) dan tidak ada responden yang pendidikan terakhirnya SMP.

\section{Tabel 4Responden Menurut Pekerjaan}

Pekerjaan Jumlah $\quad$ Persentase (\%)




\begin{tabular}{ccc}
\hline PNS & 39 & $13 \%$ \\
Karyawan Swasta & 78 & $26 \%$ \\
Ibu Rumah Tangga & 21 & $7 \%$ \\
Wiraswasta & 72 & $24 \%$ \\
Guru & 18 & $6 \%$ \\
TNI/POLRI & 6 & $2 \%$ \\
Lainnya & 66 & $22 \%$ \\
Jumlah & 300 & $100 \%$ \\
\hline
\end{tabular}

Sumber: Data primer diolah, 2021

Dari tabel diatas dapat dilihat bahwa responden yang bekerja sebagai karyawan swasta lebih dominan yaitu sebanyak 78 responden (26\%), kemudian wiraswasta 72 responden (24\%), pekerjaan lainnya 66 responden (22\%), PNS 39 responden (13\%), Ibu rumah tangga 21 responden (7\%), Guru 18 responden (6\%), TNI/POLRI 6 responden (2\%).

\subsubsection{Uji Instrumen}

Sebelum penelitian lebih lanjut, maka terlebih dahulu dilakukan uji coba instrumen penelitian dengan tujuan untuk mengetahui validitas dan reliabilitas item-item pernyataan atau kuesioner yang digunakan. Dalam kegiatan uji instrumen ini, peneliti menggunakan 30 pernyataan yang berkaitan dengan variabel enviromental consern, advertisement, electronic word of mouth dan green purchase behavior. Data yang diperoleh dari ke 300 responden dalam uji instrumen ini, kemudian dilakukan pengolahan untuk mengetahui validitas dan reliabilitas dari instrumen tersebut.

1. Uji Reliabilitas

Uji reliabilitas ini dilakukan untuk mengetahui sejauh mana keandalan instrumen penelitian sehingga setiap butir pernyataan dapat dipercaya. Berdasarkan teori yang dikemukakan oleh Nunnally dalam Ghozali (2011:48), suatu instrumen dikatakan reliabel jika memberikan nilai Cronbach Alpha $>0,70$ atau 70\%. Adapun hasil uji reliabilitas dapat dilihat pada Tabel 5 berikut ini:

Tabel 5.Hasil Uji Reliabilitas

\begin{tabular}{cccc}
\hline Variabel & Cronbach Alpha & Standar & Keterangan \\
\hline Enviromental Concern & 0,803 & $>0,70$ & Reliabel \\
Advertisement & 0,829 & $>0,70$ & Reliabel \\
Electronic Word Of Mouth & 0,858 & $>0,70$ & Reliabel \\
Green Purchase Behavior & 0,903 & $>0,70$ & Reliabel \\
\hline
\end{tabular}


Sumber: Data Primer, diolah 2021

2. Uji Validitas

Uji validitas adalah ukuran yang menunjukkan tingkat kevalidan suatu instrumen. Instrumen yang valid mempunyai validitas tinggi, sebaliknya instrumen yang kurang valid berarti memiliki validitas rendah. Menurut Arikunto (2005:171) untuk menguji validitas dipergunakan perhitungan koefisien korelasi product-moment Pearson. Dan untuk mengetahui Valid tidaknya suatu instrumen, menurut Ghozali (2009:45)

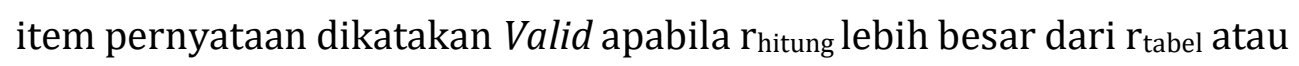
( $\left.\mathrm{r}_{\text {hitung }}>\mathrm{r}_{\text {tabel }}\right)$ dan jika $\mathrm{r}_{\text {hitung }}$ lebih kecil dari $\mathrm{r}_{\text {tabel }}$ atau $\left(\mathrm{r}_{\text {hitung }}<\mathrm{r}_{\text {tabel }}\right)$ maka item pernyataan tersebut tidak Valid. Nilai $\mathrm{df}=\mathrm{N}-2$, dengan $\mathrm{N}=30$, jadi $\mathrm{df}=28$.

a. Uji Validitas Enviromental Concern

Tabel 6. Hasil Uji Validitas Variabel Enviromental Concern

\begin{tabular}{ccccc}
\hline $\begin{array}{c}\text { Item } \\
\text { Pernyataan }\end{array}$ & $\mathbf{r}_{\text {hitung }}$ & $\mathbf{r}_{\text {tabel }}$ & Keterangan & Signifikansi \\
\hline 1 & 0,832 & 0,3610 & Valid & 0,000 \\
2 & 0,767 & 0,3610 & Valid & 0,000 \\
3 & 0,867 & 0,3610 & Valid & 0,000 \\
4 & 0,677 & 0,3610 & Valid & 0,000 \\
5 & 0,608 & 0,3610 & Valid & 0,000 \\
6 & 0,499 & 0,3610 & Valid & 0,002 \\
\hline
\end{tabular}

Sumber: Data Primer, diolah 2021.

Berdasarkan Tabel 6 di atas, dapat disimpulkan bahwa semua item pernyataan untuk variabel environmental concern adalah valid $\mathrm{r}_{\text {hitung }}>$ rtabel.

b. Uji Validitas Advertisement

Tabel 7. Hasil Uji Validitas Variabel Advertisement

\begin{tabular}{ccccc}
\hline $\begin{array}{c}\text { Item } \\
\text { Pernyataan }\end{array}$ & $\mathbf{r}_{\text {hitung }}$ & $\mathbf{r}_{\text {tabel }}$ & Keterangan & Signifikansi \\
\hline 1 & 0,729 & 0,3610 & Valid & 0,000 \\
2 & 0,716 & 0,3610 & Valid & 0,000 \\
3 & 0,783 & 0,3610 & Valid & 0,000 \\
4 & 0,826 & 0,3610 & Valid & 0,000 \\
5 & 0,790 & 0,3610 & Valid & 0,000 \\
\hline
\end{tabular}

Sumber: Data Primer, diolah 2021.

Berdasarkan Tabel 7 di atas, dapat disimpulkan bahwa semua item pernyataan untuk variabel edvertisement adalah valid $\mathrm{r}_{\text {hitung }}>\mathrm{r}_{\text {tabel. }}$. 
Dampak Enviromental Concern, Advertisement Dan Electronic Word Of Mouth Pada Green

Purchase Behavior

c. Uji Validitas Electronic Word Of Mouth

Tabel 8. Hasil Uji Validitas Variabel Electronic Word Of Mouth

\begin{tabular}{ccccc}
\hline $\begin{array}{c}\text { Item } \\
\text { Pernyataan }\end{array}$ & $\mathbf{r}_{\text {hitung }}$ & $\mathbf{r}_{\text {tabel }}$ & Keterangan & $\begin{array}{c}\text { Signifikans } \\
\mathbf{i}\end{array}$ \\
\hline 1 & 0,789 & 0,3610 & Valid & 0,000 \\
2 & 0,716 & 0,3610 & Valid & 0,000 \\
3 & 0,877 & 0,3610 & Valid & 0,000 \\
4 & 0,699 & 0,3610 & Valid & 0,000 \\
5 & 0,799 & 0,3610 & Valid & 0,000 \\
6 & 0,706 & 0,3610 & Valid & 0,000 \\
\hline
\end{tabular}

Sumber: Data Primer, diolah 2021.

Berdasarkan Tabel 8 di atas, dapat disimpulkan bahwa semua item pernyataan untuk variabel electronic word of mouth adalah valid rhitung $>r_{\text {tabel. }}$

d. Uji Validitas Variabel Green Purchase Behavior

Tabel 9. Hasil Uji Validitas Variabel Green Purchase Behavior

\begin{tabular}{ccccc}
\hline $\begin{array}{c}\text { Item } \\
\text { Pernyataan }\end{array}$ & $\mathbf{r}_{\text {hitung }}$ & $\mathbf{r}_{\text {tabel }}$ & Keterangan & Signifikansi \\
\hline 1 & 0,797 & 0,3610 & Valid & 0,000 \\
2 & 0,810 & 0,3610 & Valid & 0,000 \\
3 & 0,892 & 0,3610 & Valid & 0,000 \\
4 & 0,878 & 0,3610 & Valid & 0,000 \\
5 & 0,861 & 0,3610 & Valid & 0,000 \\
\hline
\end{tabular}

Sumber: Data Primer, diolah 2021.

Berdasarkan Tabel 9 di atas, dapat disimpulkan bahwa semua item pernyataan untuk variabel green purchase behavior adalah valid rhitung $>$ rtabel.

3.1.3. Analisis Data dan Pembuktian Hipotesis

Bentuk umum persamaan regresi linier berganda dalam penelitian ini dinyatakan dengan rumus sebagai berikut :

$$
\mathrm{Y}=\mathrm{a}+\mathrm{b}_{1} \mathrm{X}_{1}+\mathrm{b}_{2} \mathrm{X}_{2}+\mathrm{b}_{3} \mathrm{X}_{3}+\mathrm{e}
$$

Adapun dari hasil analisis regresi berganda diperoleh nilai koefisien regresi $(\beta)$ yang ditunjukkan dalam Tabel 10 di bawah ini.

Tabel 10. Hasil Koefisien Regresi ( $\beta$ )

\begin{tabular}{ll}
\hline Variabel & Koefisien Regresi $(\beta)$ \\
\hline Konstanta & 10.297 \\
Enviromental Concern & 0,107 \\
Advertisement & 0,136 \\
\hline
\end{tabular}



0,161

Sumber : Data Primer diolah 2021

Dengan memperhatikan model regresi dan Tabel 10 diatas, maka didapatkan persamaan variabel-variabel yang mempengaruhi green purchase behavior konsumen produk hijau sebagai berikut:

$$
\mathrm{Y}=10.297+0,107 \mathrm{X}_{1}+0,136 \mathrm{X}_{2}+0,161 \mathrm{X}_{3}
$$

\subsubsection{Uji Signifikan Parameter Individual (Uji Statistik t).}

Untuk menguji pengaruh variabel independen secara individual dalam menerangkan variasi variabel dependen (Ghozali, 2009:84). Untuk melihat pengaruh variabel enviromental concern, advertisement, electronic word of mouth terhadap green purchase behavior, maka dilakukan uji statistik t.

Tabel 11. Hasil Uji Parsial Variabel Independen

\begin{tabular}{lcccc}
\hline \multicolumn{1}{c}{ Variabel } & $\mathrm{t}_{\text {hitung }}$ & $\mathrm{t}_{\text {tabel }}$ & $\mathrm{Sig}$ & Keterangan \\
\hline $\begin{array}{l}\text { Enviromental } \\
\text { concern }\end{array}$ & 2,016 & 1,6499 & 0,045 & $\begin{array}{l}\text { Ha diterima/ } \\
\text { sig. pada 5\% }\end{array}$ \\
Advertisement & 1,993 & 1,6499 & 0,047 & $\begin{array}{l}\text { Ha diterima/ } \\
\text { sig. pada 5\% }\end{array}$ \\
Electronic WOM & 3,282 & 1,6499 & 0,000 & $\begin{array}{l}\text { Ha diterima/ } \\
\text { sig. pada 5\% }\end{array}$ \\
\hline
\end{tabular}

Sumber : Data Primer, diolah 2021

Berdasarkan Tabel 11 di atas, diketahui bahwa nilai thitung variabel environmental concern sebesar 2,016, sedangkan nilai ttabel sebesar 1,6499, sehingga dapat disimpulkan bahwa thitung $=2,016>t_{\text {tabel }}=1,6499$. Hal ini berarti bahwa $\mathrm{H}_{\mathrm{a}}$ diterima, Artinya ada pengaruh yang positif signifikan antara environmental concern terhadap green purchase behavior pada konsumen produk hijau di Kabupaten Rembang secara parsial.

Berdasarkan Tabel 11 di atas, diketahui bahwa nilai thitung variabel advertisement sebesar 1,993, sedangkan nilai tabel sebesar 1,6499, sehingga dapat disimpulkan bahwa $t_{\text {hitung }}=1,993>t_{\text {tabel }}=1,6499$. Hal ini berarti bahwa $\mathrm{H}_{\mathrm{a}}$ diterima, Artinya ada pengaruh yang positif signifikan antara advertisement terhadap green purchase behavior pada konsumen produk hijau di Kabupaten Rembang secara parsial.

Berdasarkan Tabel 11 di atas, diketahui bahwa nilai thitung variabel electronic word of mouth sebesar 3,283, sedangkan nilai tabel sebesar 1,6499, sehingga dapat disimpulkan bahwa $t_{\text {hitung }}=3,283>t_{\text {tabel, }}=1,6499$. 
Hal ini berarti bahwa $\mathrm{H}_{\mathrm{a}}$ diterima, Artinya ada pengaruh yang positif signifikan antara electronic word of mouth terhadap green purchase behavior pada konsumen produk hijau di Kabupaten Rembang secara parsial.

Untuk mengetahui pengaruh secara simultan antara enviromental concern, advertisement dan electronic word of mouth terhadap green purchase behavior konsumen produk hijau di Kabupaten Rembang dapat dilihat hasil uji simultan pada Tabel 12 berikut ini :

Tabel 12. Hasil Uji Simultan Variabel Enviromental Concern, Advertisement, Electronic Word Of Mouth terhadap Green Purchase Behavior Konsumen Hijau di Kabupaten Rembang

\begin{tabular}{|c|c|c|c|c|}
\hline Variabel & $\mathrm{F}_{\text {hitung }}$ & $F_{\text {tabel }}$ & Sig. & Keterangan \\
\hline $\begin{array}{l}\text { Enviromental concern, } \\
\text { Advertisement, Electonic WOM, Green } \\
\text { Purchase Behavior }\end{array}$ & 7,214 & 6,63 & 0,000 & $\begin{array}{c}\text { Ha } \\
\text { diterima/ } \\
\text { signifikan. } \\
\text { pada } 5 \%\end{array}$ \\
\hline
\end{tabular}

Sumber : Data Primer, diolah 2021

Melalui uji ANOVA atau F-test pada Tabel 12, diperoleh nilai $F_{\text {hitung }}$ sebesar 7,214 dengan tingkat signifikansi 0,000. Berdasarkan hasil tersebut dapat disimpulkan bahwa variabel enviromental concern, advertisement dan electronic word of mouth secara simultan atau bersama-sama berpengaruh signifikan terhadap green purchase behavior karena $\mathrm{f}_{\text {hitung }}=7,214>\mathrm{ftabel}=$ 6,63 dan tingkat signifikansi sebesar 0,000 atau kurang dari 0,05.

. Tabel 12 berikut menjelaskan tentang hasil uji determinasi yang dilihat pada koefisien determinasi yang terletak pada tabel Model Summary berikut:

Tabel 13. Hasil Uji Determinasi Variabel Enviromental Concern, Advertisement, Electronic Word Of Mouth terhadap Green Purchase Behavior Konsumen Hijau di Kabupaten Rembang

\begin{tabular}{ll}
\hline Model & $\begin{array}{l}\text { Adjusted } \\
R \text { Square }\end{array}$ \\
\hline Dampak Variabel Enviromental Concern, Advertisement, Electronic & 0,059 \\
$\begin{array}{l}\text { Word Of Mouth terhadap Green Purchase Behavior Konsumen Hijau } \\
\text { di Kabupaten Rembang }\end{array}$ & \\
\hline
\end{tabular}
Sumber : Data Primer, diolah 2021

Berdasarkan Tabel 13 di atas, maka dapat diketahui bahwa besarnya 
koefisien adjusted $R$ square adalah 0,059. Dengan nilai adjusted $R$ square 0,059, maka dapat diartikan bahwa variabel enviromental concern, advertisement dan electronic word of mouth dapat menjelaskan pengaruhnya terhadap green purchase behavior sebesar 5,9\%. Adapun sisanya sebesar 94,1\% dipengaruhi faktor lain di luar model penelitian.

\section{PEMBAHASAN}

Dari hasil penelitian, menunjukkan bahwa enviromental concern, advertisement dan electronic word of mouth berpengaruh signifikan terhadap green purchase behavior.

a. Pembahasan Variabel Enviromental Concern

Hasil penelitian ini menunjukkan bahwa hipotesis pertama yaitu, variabel enviromental concern berdampak secara signifikan terhadap variabel green purchase behavior. Hasil penelitian ini sama dengan hasil dari berbagai peneliti (Kalafatis et al., 1999; Laroche et al., 2001: Manakotla \& Jauhari, 2007) peningkatan kepedulian lingkungan mengarah pada peningkatan pola perilaku menuju pembelian produk ramah lingkungan. Pembelian produk ramah lingkungan merupakan salah satu bentuk sikap green purchase behavior. Dari hasil kuesioner menunjukkan ada responden yang memberikan pernyataan kurang setuju hingga sangat tidak setuju terhadap pernyataan yang disajikan dalam kuesioner. Melalui beberapa wawancara terbuka akan pernyataan tersebut, responden memberikan keterangan bahwa beberapa dari mereka belum terlalu mendalam pengetahuannya mengenai isu-isu lingkungan terkini dan kaitannya dengan produk hijau yang mereka konsumsi. Ada yang memberikan keterangan bahwa konsumsi produk hijau untuk merawat kesehatannya secara pribadi.

b. Pembahasan Variabel Advertisement

Hasil penelitian ini menunjukkan hipotesis kedua yaitu variabel advertisement berdampak secara signifikan terhadap green purchase behavior. Hasil penelitian ini menguatkan pernyataan Oh \& Xu (2003) mengatakan bahwa media massa memiliki pengaruh vital terhadap kehidupan dan gaya berpikir kita. Artinya iklan produk hijau akan mempengaruhi kehidupan dan gaya 
berfikir hingga menjadikan kita memiliki perilaku hijau atau green purchase behavior. Iklan produk hijau yang sering tampil di sosial media seringkali menarik perhatian responden dan mereka merasa ingin mencobanya produk tersebut. Dari iklan yang muncul di media sosial tersebut memberikan kemudahan pada konsumen untuk mengakses atau membeli produk hijau. Keterangan dari responden melalui wawancara terbuka, mereka tidak begitu terpengaruh oleh jarak, meskipun di Rembang tidak banyak terdapat produk hijau, namun melalui media sosial mereka bisa menjangkau produk tersebut.

c. Pembahasan Variabel Electronic Word Of Mouth

Hasil penelitian ini menunjukkan bahwa hipotesis ketiga yaitu variabel electronic word of mouth berdampak signifikan terhadap green purchase behavior. Hasil ini sama dengan penelitian yang dilakukan oleh Hayat dan Ahmed (2017), menyatakan bahwa enviromental concern, advertisement dan WOM secara signifikan berdampak pada perilaku pembelian hijau di Pakistan. WOM sekarang dianggap sebagai salah satu kekuatan utama untuk pengambilan keputusan di pasar (Zamil, 2011). Apapun yang disampaikan oleh netizen akan menjadi rujukan oleh calon konsumen. Dari wawancara terbuka kepada beberapa responden menjelaskan bahwa mereka mendapatkan begitu banyak ulasan dari internet mengenai produk hijau. Mereka akan memilih produk hijau yang memiliki ulasan positif dan tidak berisiko. Dengan ulasan positif tersebut akan membuat mereka melakukan pembelian atau mengkonsumsi produk hijau yang diiklankan.

d. Pengaruh Secara Simultan (Uji F)

Hasil penelitian ini menunjukkan bahwa variabel enviromental concern, advertisement dan electronic word of mouth berpengaruh secara bersamasama terhadap green purchase behavior, hal ini memperkuat hasil penelitian sebelumnya yang dilakukan oleh Hayat dan Ahmed (2017), menyatakan bahwa enviromental concern, advertisement dan WOM secara signifikan berdampak pada perilaku pembelian hijau di Pakistan.

\section{KESIMPULAN}

Berdasarkan hasil penelitian dan pembahasan yang telah dikemukakan di depan, 
maka dapat disimpulkan sebagai bahwa Enviromental concern mempunyai pengaruh positif dan signifikan terhadap green purchase behavior konsumen produk hijau di Kabupaten Rembang. Berdasarkan hasil penelitian dan kesimpulan di atas, maka saran yang dapat diajukan peneliti yaitu, model penelitian ini bisa digunakan untuk meneliti di lokasi yang lebih luas supaya bisa melihat dampaknya lebih luas dan untuk penelitian selanjutnya hendaknya dapat meneliti faktor-faktor lain yang berpengaruh terhadap green purchase behavior selain enviromental concern, advertisement dan electronic word of mouth, sehingga penelitian selanjutnya diharapkan dapat menyempurnakan penelitian yang ada.

\section{REFERENSI}

Arikunto, S. 2006. Metode Penelitian Kualitatif. Jakarta: Bumi Aksara.

Chan, W. W. \& Lam, J. C. (2002). Prediction of pollutant emission through electricity consumption by the hotel industry in Hong Kong. International Journal of Hospitality Management 21, 381-391.

D'Souza, C, Taghian, M \& Lamb, P 2006, 'An empirical study on the influence of environmental labels on consumers', Corporate Communications: An International Journal, vol. 11(2), hal. 162-173.

Ghozali, Imam, 2001, Aplikasi Analisis Multivariate Dengan Program SPSS. Semarang: Universitas Diponegoro.

Goldsmith, RE. And Horowitz, D. 2006. Measuring Motivation For Online Opinion Seeking. Journal Of Interactivr. Vol. 6 No. 2, pp.1-16.

Goyette, I., Ricard,L.,Bergeron,J. \& Marticotte, F (2010). e-WOM Scale: WordofMouth Measurement Scale for e-Services Context, Canadian Journal of Administrative Sciences,27(1),5-23.

Gruen,T.W., Osmonbekov,T.,Czaplewski,A.J (2006). eWOM: the impact of customer-to-customer online know-how exchange on customer value and loyalty, Journal of Business Research,59(4),449-456.

Hiqmah, Faizatul, 2016, Observasi tren perilaku pembelian hijau konsumen Indonesia di berbagai industri, Journal of Business and Banking Volume 6 Number 1 May - October 2016 pp. 27- 44: STIE Perbanas Press 2016.

Jain, S. K., \& Kaur, G. (2004). Green marketing: An attitudinal and behavioural analysis of Indian consumers. Global Business Review, 5(2), 187-205.

Kalafatis, S. P., Pollard, M., East, R., \& Tsogas, M. H. (1999). Green marketing and Ajzen's theory of planned behaviour: a cross-market examination. Journal of Consumer Marketing, 16(5): 441-460

Kotler, Philip \& Garry Armstrong. 2010. Prinsip-Prinsip Pemasaran, Jilid 1 dan 2 Edisi Kedua Belas. Jakarta : Erlangga

Kottler dan Keller, 2012, Manajemen Pemasaran Edisi 12, Jakarta: Erlangga.

Laroche, M., Bergeron, J. \& Barbaro-Forleo, G., (2001). Targeting consumers who are willing to pay more for environmentally friendly products. Journal of 
Consumer Marketing 18 (6), 503-520.

Lukiarti, MM, 2019, Pengaruh Kepedulian Lingkungan Dan Sikap Terhadap Minat Beli Produk Hijau (Studi Kasus Pada Konsumen Produk Hijau di Kabupaten Rembang). Bulletin Bisnis dan Manajemen Vol. 5, page 15-28.

Manaktola, K., \& Jauhari, V. (2007). Exploring consumer attitude and behaviour towards green practices in the lodging industry in India. International Journal of Contemporary Hospitality Management, 19(5), 364377.

Papadopoulos, A. M., \& Giama, E. (2009). Rating systems for counting buildings' environmental performance. International Journal of Sustainable Energy, 28(1-3), 29-43.

Schultz, P. (2000). New Environmental Theories: Empathizing With Nature: The Effects of Perspective Taking on Concern for Environmental Issues. Journal of social issues, 56(3), 391-406.

Shrum, L. J., McCarty, J. A., \& Lowrey, T. M. (1995). Buyer characteristics of the green consumer and their implications for advertising strategy. Journal of Advertising, 24(2), 71-82.

Sinappan, P \& Rahman, AA 2011, 'Antecedents of green purchasing behavior among Malaysian consumers', International Business Management, vol. 5 No. 3, hal.129-139.

Situmorang, James R. 2011. Pemasaran Hijau Yang Semakin Menjadi Kebutuhan Dalam Dunia Bisnis. Jurnal Administrasi Bisnis, Vol. 7, no 2, hal 131-142.

Sugiyono. 2008. Metode Penelitian Kuantitatif Kualitatif dan R\&D. Bandung : ALFABETA

Suki, N. M. (2013). Green Awareness Effects on Consumers' Purchasing Decision: Some Insights From Malaysia. Ijaps, 9(2), 49-63.

Rashid, NRNA 2009, 'Awareness of eco-label in Malaysia green market ing initiative', International Journal of Business and Management, vol. 4(8), hal. 132-141.

Uma, Sekaran. 2006. Research Methods For Business (Metode Penelitian untuk Bisnis). Edisi empat buku 1. Salemba Empat.

Vivekananthan, V. (2010). A study on influence of advertisement in consumer brand preference (special reference to soft drink market in Manmunnai north ds division Batticaloa).

Yazdanifard, R., \& Mercy, I. E. (2011). The impact of green marketing on customer satisfaction and environmental safety. In 2011 International Conference on Computer Communication and Management (Vol. 5, pp. 637-641).

https://ekonomi.kompas.com/read/2018/02/15/093533926/survei-nielsen-mediadigital-dan-media-konvensional-saling-melengkapi?page=all.Diakses, 14/03/2021; 